\title{
Flood Depth-Damage Functions for Built Environment
}

\author{
Aimilia Pistrika • George Tsakiris • Ioannis Nalbantis
}

Received: 27 May 2014 / Accepted: 1 October 2014 / Published online: 1 November 2014

(C) Springer International Publishing Switzerland 2014

\begin{abstract}
A conventional approach for the economic estimation of direct flood damage to buildings is using the method of depth-damage functions. However, there are few publications that describe in detail the derivation of depth-damage functions based on actual flood damage data. It still remains an open issue whether a site-specific depthdamage function can be applied to another region with similar climate and building conditions. This paper aims at demonstrating a step-by-step methodology for devising depth-damage functions using data from a flood event which occurred in Moschato, a suburb of Athens, Greece in July 2002. It also compares the developed depth-damage functions to functions from other areas with similar conditions. In the case study, the damage percentage is calculated per category of flood-affected property on the basis of relief payments. The replacement cost of the affected components of a building structure and the market value of each category of flood-affected property are estimated in order to develop depth-damage relationships for building structures. The local depth-damage function for residential use is compared to generalized functions and a site-specific function developed for the urban area of Palermo, Italy. Differences and similarities in damage datasets are examined and explained by related causative factors such as structural or architectural features of buildings. Finally, the application of both of the above functions to a third case (the Erasinos river basin in Attica, Greece) resulted in a fair difference (9\%) in the estimation of the expected average annual direct damage to residential buildings.
\end{abstract}

Keywords Flood damage - Depth-damage function - Residential areas · Replacement cost · Damage percentage $\cdot$ Moschato $\cdot$ Palermo $\cdot$ Erasinos river

\footnotetext{
A. Pistrika $(\bowtie) \cdot$ G. Tsakiris $\cdot$ I. Nalbantis

Centre for the Assessment of Natural Hazards and Proactive Planning, Laboratory of Reclamation Works and Water Resources Management, School of Rural and Surveying Engineering, National Technical University of Athens, Heroon Polytechniou 9, Zographou, 15780 Athens, Greece e-mail: aimilia.pistrika@gmail.com

G. Tsakiris

e-mail: gtsakir@central.ntua.gr

I. Nalbantis

e-mail: nalbant@central.ntua.gr
} 


\section{Introduction}

\subsection{Objective}

According to the Emergency Disasters Database (EM-DAT), between 2001 and 2011 the number of large-scale floods around Southern Europe increased with respect to the previous decade to over 120 major events causing some 345 fatalities and an estimated economic loss of at least $€ 12$ billion. Rising rate of urbanization, together with high population density, especially in coastal areas, contribute to augmenting flood vulnerability in the region. In the Mediterranean region, flash flooding is the most common type of inundation since the majority of flood events is induced by intense rainfall occurring in short time periods.

Greece is no exception to this issue. Although regular recording of flood events by civil protection agencies started relatively recently in Greece, an extensive catalogue of flooding phenomena during the last 130 years has been compiled (Diakakis et al. 2012). In this catalogue, in total, 545 events are reported, which caused 686 casualties and extensive damage across the country. Also, urban centres, like Athens, tend to present flood recurrence rates that are higher than those of mountainous and rural areas.

Recently the European Union set in force the Floods Directive (2007/60/EC) (European Council 2007) on the assessment and management of flood risks, and thus, detailed flood hazard and flood risk mapping in identified flood prone areas became a demanding task requiring damage estimation in economic terms. Tsakiris et al. (2009) point out several issues of technical nature related to difficulties in implementing the directive in Greece in the context of climatic and institutional conditions of Mediterranean countries. Advanced numerical models for detailed flood simulations could be used, particularly in floodplains characterised by mild terrain and built environment. Tsakiris and Bellos (2014) and Bellos and Tsakiris (2014) have proposed a new powerful numerical hydrodynamic model that simulates flood routing in two dimensions. The model has been tested successfully in built up areas.

The accuracy of flood hazard assessments is limited by the fact that most drainage basins, including urban ones, are poorly gauged (Nalbantis 1995) or even ungauged and affected by changes such as forest fires (Nalbantis and Lymperopoulos 2012; Batelis and Nalbantis 2014). When advancing a step further, specifically to flood damage assessments, the data scarcity problem is accentuated and damage estimation methods inevitably become crude (Meyer and Messner 2005; Merz et al. 2010). Although direct flood damage estimation to building structures is commonly accomplished by applying the method of depth-damage function (Appelbaum 1985; Penning-Rowsell and Fordham 1994; Smith 1994; USACE 1996), there are few publications (Büchele et al. 2006; Reese 2003) that describe in detail the development of an empirical relationship between the recorded flood depth and the estimated damage to buildings after a flood event. The techniques for establishing depth-damage functions in urban areas are not standardized (Appelbaum 1985); additionally, the uncertainty involved when applying a site specific depth-damage function to another region is still under research.

The aim of the present paper is to describe step-by-step the development of an empirical, depth-damage percentage relationship - damage percentage will be defined in Section 3.3based on actual flood depths and damage data collected from detailed field surveys, and then, to compare the produced functions with other ones which were developed elsewhere. A part of the urban area of the Moschato municipality of Athens, Greece, has been selected as the case study. The damage dataset was collected in the aftermath of a flood event that occurred in July 2002. Actions of recording maximum flood depths and identifying affected components of building structures took place in the field immediately after the flood event by groups of specialized engineers. The aim of the field survey was to estimate the actual level of damage 
per flood-affected building and, based on these estimates, compensate the flood victims (expost damage estimation) within the study area. The outline of the paper is as follows. The remainder of the current section summarizes the state of the art in direct flood damage estimation to buildings. Section 2 refers to basic principles of the method of depth-damage functions. Section 3 describes the damage dataset and the estimation of damage percentage. Analysis of the relationship between flood depth and damage percentage, produced per building use, is presented in Section 4. Section 5 compares the derived empirical function for residential use with other depth-damage functions for the same use; at first, several depthdamage functions, produced at the regional level and widely used in the United States, are compared with the one developed in Moschato, and then, a site-specific depth-damage function, developed in an urban area of Palermo (Sicily, Italy) is examined. The main similarities and differences between the two damage datasets of Palermo and Moschato study areas are outlined and the results of applying the Palermo function and the Moschato function to a third case are discussed. Concluding remarks are presented in Section 6.

\subsection{A General Approach in Damage Estimation}

In general, the estimation of direct flood damage to buildings involves two related steps (Pistrika and Jonkman 2009). The first step is the analysis of the structural damage caused by the flood effects. This is determined by the flood actions (or loads) and the building resistance (Kelman and Spencer 2004). The next step is the economic estimation of the physical damages. To convert the physical structural damage to economic estimates of damage percentage, insight in both the pre-disaster market value and the replacement cost of each building is required.

In practice, the estimation of direct damage to buildings is often accomplished by applying the method of depth-damage function that relates flood characteristics directly to the economic value of damage without investigating the physical mechanisms that cause the structural damage. The flood characteristics used are in most cases the results of flood simulations using the probability distribution of annual peak discharges together with the stage-discharge curves. For instance, the investigation of the relationship between flood characteristics and the economic damage to residential buildings due to flooding of New Orleans after hurricane Katrina was based on the results of hydrodynamic flood simulations (Pistrika and Jonkman 2009). Pistrika (2010a) formulated damage-frequency relationships under flood simulation scenarios in GIS environment in a case study located in the Erasinos basin within Eastern Attica Prefecture.

Apart from the problem of model calibration, the procedures of flood simulation and routing are well-proved procedures, and therefore, it has been argued (Motayed and Krishnamurthy 1979) that in many cases uncertainty arising from hydrologic and hydraulic simulations is not as significant as the uncertainty of the economic damage evaluation.

Depth-damage functions can be based on actual damage data from historical floods. By definition, depth-damage functions include the water depth as the main determinant of direct damage (Appelbaum 1985; Smith 1994; USACE 1996; Penning-Rowsell and Fordham 1994; Pistrika 2010b). However, many more factors such as flow velocity, duration of flooding, sediment load, contamination, the existence of a flood warning system, and the effectiveness of emergency response during a flood event (Smith 1994; Kelman and Spencer 2004; Merz et al. 2004; Pistrika and Jonkman 2009; Pistrika 2010b; Tsakiris 2014) may influence the severity and the extent of flood damage to buildings. Flood damage models rarely include all these factors. 
For all the above reasons, many researchers argue that the uncertainty of adopting the depth-damage approach may be significant since flood depth and building characteristics only explain a part of the data variance (Merz et al. 2004; Egorova et al. 2008). The question whether the method of depth-damage function is the appropriate approach in direct damage estimation depends very much on the spatial level of analysis and the availability of resources and data (Messner et al. 2007). Therefore, it is worthwhile concentrating on the evaluation of the studied damage dataset through detailed analyses in order to establish reliable depthdamage relationships.

\section{The Method of Depth-damage Function}

\subsection{Types of Depth-damage Function}

According to the kind of information used in developing depth-damage functions, two main types of such functions can be distinguished: the empirical functions, which use damage data collected after flood events, and the synthetic functions, which employ theoretical damage data collected via inventories or interviews and are based on hypothetical analyses and expert judgments.

A strong argument in favour of empirical curves is that actual damage information is more accurate than the subjective what-if damage analysis, and hence actual damage data better reflect variability within one category of building use (Merz et al. 2004). It is noted that building categories are specified for each case study and will be discussed in section 3 . Detailed damage surveys in the field after a flood event are uncommon since they require much effort and time per unit of area to carry them out. Moreover, transferability of functions in time and space is in question due to differences in flood experience, warning time and building type, and contents subject to flood damage. On the contrary, the transferability and comparability of the damage estimates is a strong advantage for synthetic functions (Smith 1994).

Apart from the distinction between the empirical and synthetic damage functions, the depth-damage functions are discerned between relative or absolute ones. Relative functions use ratios of the absolute monetary amounts of damage to the value of assets, i.e., they express the flood damage as a percentage of the total replacement value of a flood-affected property. Absolute damage functions employ the absolute monetary amounts of damage per element at risk, and thus, their period of validity is short. The depth-damage relationships developed in this study fall within the relative function category. The selection of this category is dictated by the fact that relationships of this category almost never need updating, and thus, the percentages remain fairly unchangeable with time (Appelbaum 1985), since they do not depend on changes in market values of properties due to inflation and/or changes in local economy or development status (Krzysztofowicz and Davis 1983). Such changes result in relative changes of the numerator and the denominator of Eq. (1) (given in section 3) which are very close to one another. Hence, the validity of the developed functions is long lasting. Given that damage data scarcity is almost always the case with flood damage estimation studies, relative damage functions are naturally the first choice in such studies.

In the present paper, the depth-damage approach is based on empirical data of actual, expost flood damages, collected during site inspections immediately after the flood event. Hence, flood damage analysis focuses on the development of empirical functions. Additionally, the dimensionless type of functions is preferred in order to improve the transferability of the empirical functions in time, thus minimising the need for updating of these functions. 


\subsection{Spatial Level of Damage Analysis}

The size of the area under study — denoted as the spatial level of damage analysis - is important to be consistent with the selected method for damage estimation. Usually, the most detailed damage models are restricted to small areas due to resource limitations, while for areas of regional or national size one has to rely on less detailed damage models.

Messner and Meyer (2005) identified three levels of damage analysis: (a) macro-scale analysis for national and even international studies, e.g., a sub-basin of a transboundary river basin; (b) meso-scale analysis for regional studies that consider aggregated land use units; and (c) micro-scale analysis for local studies that use a per building approach. However, by presenting examples of damage evaluation methodologies throughout Europe, they argued that the boundaries of three levels of spatial damage analysis are not clear. Messner et al. (2007) recommend that a macro-, meso- or micro-approach should depend not only on the size of the study area but also on other factors that support the selection of a damage method for a specific study (e.g., differentiation of land use categories).

According to recent studies (Merz et al. 2004; Thieken et al. 2008; Pistrika and Jonkman 2009), the spatial level of detail of a damage analysis is a determining factor for the correlation between predictions and observations. At a high level of detail and for a limited sample size of buildings, the variations in building damage may be considerable, which reduces the correlation mentioned above. In this paper, damage analysis is performed at the micro-scale spatial level within an urban environment of high building density. The actual damage dataset refers only to the structure of the flood-affected properties and no building content is included. The assumption of a uniform spatial distribution of building structures is made, which results in a uniform asset distribution per category of flood-affected property and per building use (e.g., residential, commercial etc.) as the latter two terms are defined in each case study; this overcomes expected variations in damage estimates at the micro-scale level and allows the implementation of the method of depth-damage function.

The following section describes the categorization of the flood-affected buildings of the dataset under study. The categorization aims to achieve the maximum possible uniformity in the asset (property) distribution within every building category.

\section{Damage Dataset Used}

\subsection{Overview of the Area Under Study}

The flood-affected buildings of the dataset are categorized with the aim to achieve the maximum possible uniformity in the asset (property) within every building category. On the 8th of July 2002, an overflow of Kifisos River in Athens, Greece caused extensive damage over municipalities lying on the riverine floodplain. Based on the records of the nearest rainfall station (Egaleo rainfall station), total point rainfall depth was equal to $105 \mathrm{~mm}$ with an average rainfall intensity of $40 \mathrm{~mm} / \mathrm{h}$. The return period of the flood event was estimated at 180 years (Macheras Consulting Engineers SA 2002). The river that was restrained by levees at both its sides, overflowed at cross sections where the width was particularly small due to technical works in progress. Notable water depths were recorded in the Moschato municipality, due to the zone topography and, mostly, due to inadequate conveyance capacity of both the river and the local network of storm sewers. Figure 1 shows the extent of the flooded area in Moschato municipality and also includes a location map of Moschato in greater Athens area and in Greece. Moreover, both poor flood protection measures and slow response of the civil 


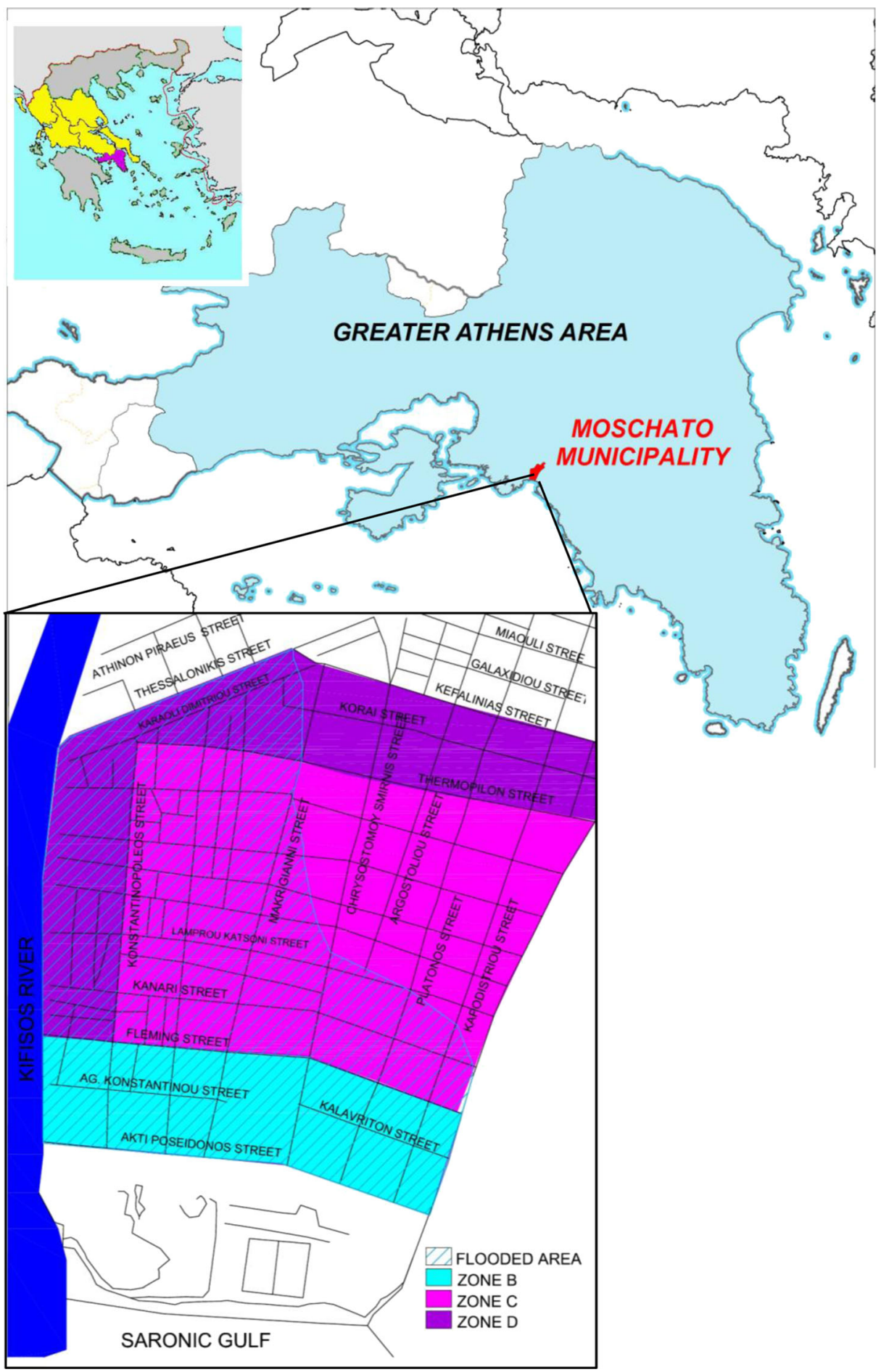

Fig. 1 Location map of Moschato municipality in the greater Athens area, Greece - Boundaries of land zones identified within the flooded area in Moschato municipality 
protection agency resulted in greater areal expansion and longer duration of the inundation incident, far more than it was expected from the flood event alone.

As a result, 669 residences, 257 commercial stores and 238 warehouses were registered as flood-affected properties in the Moschato municipality alone. Moschato municipality suffered by far the most extensive damage to buildings. Also, the highest flood depths were recorded there. The damage analysis focuses on the damage sustained within the Moschato boundaries for one more reason: the distribution of buildings per use and per property value can be assumed uniform enough to allow the development of depth-damage functions. All inundated residential buildings were flood-affected at the ground floor and/or the basement. All affected commercial stores were located at the ground floor of multi-storey buildings whereas all warehouses were located at the basement. This classification per building use (residential, commercial, warehouse) was applied during the field survey, and was, therefore, maintained in the damage analysis.

The studied damage dataset is restricted to only 129 properties ( 87 residences, 17 stores and 25 warehouses) due to the limited public access to the damage archives of the initial damage dataset of the responsible authority of the Ministry of Public Works and Environment. The limitations were mainly the result of strict enforcement of the law about the protection of data of private nature.

\subsection{Overview of Damage Dataset}

The damage dataset was collected in the field via inspections and surveys by groups of engineers appointed by the Earthquake Rehabilitation Centre (2010) of the Ministry of Public Works and Environment to determine eligibility for governmental housing assistance.

An analytical methodology was followed. Standardized guide sheets - designed by the Ministry for inspecting damaged buildings - were used to differentiate direct damage in fourteen (14) component categories of a structure (internal and external plaster, windows, doors, suspended ceilings etc.).

The inspectors measured the size of the flood-affected components of the structure and they evaluated ad hoc the damage amounts of the flood-affected components on the basis of the unit cost of building materials. No property contents were included in the damage estimates.

Summing the replacement costs of the various affected components per property led to the calculation of the total damage amount per property, in monetary values of 2002 . The relief payments to the flood victims were estimated based on the total damage amount. Also, during site inspection per property, flood depth and extent of the flooded area were recorded. It is worth mentioning that only non-structural damage to buildings was observed in the field survey. Non-structural damage is defined as the damage to those building components which are not responsible for the static behavior of the building structure. Differences in the social status of home owners, the direct damage incurred to gardens, roads, cars and indirect damages such as the missing income due to suspended commercial and industrial activities and/or public services, and finally, the costs of the special maintenance works have been ignored.

As already mentioned, due to limited public access to the collected damage records, only parts of the records are used in the present analysis. A damage dataset of 129 flood-affected buildings was formed for the purposes of statistical analysis, which includes the following information for every property: location (street address, zip code, planning district), building use (residential, commercial, other), number of storeys, existence of basement, age of property, main construction material, information on whether or not the central heating system of the property was flood-affected, total damage amounts in monetary values of 2002, flood depth 
and extent of inundation. The extent of inundation is assumed to be equal to the area of the ground floor, except if it was stated differently.

Damage to household equipment (e.g., electric appliances, furniture etc.) was not recorded during the field survey with the exception of the damage to the central heating system of a building whose replacement cost is relatively high (estimated at approximately $500 €$, in prices of 2002). Since a central heating system is usually located either at the basement or at the ground floor of a multi-storey building, the damage to central heating due to flooding indicates a separate type of direct damage during the field survey. In the present analysis, the term 'special damage' is adopted to describe it.

\subsection{Damage Percentage Calculation}

Damage percentage is defined as the ratio of the total cost to replace the damaged components of a flood-affected property to the pre-disaster market value of the property (USACE 1980, 1982):

$$
\text { Damage Percentage }=\frac{\text { Cost of Repairs }}{\text { Market Value of Building }}
$$

Damage percentage values vary between 0 and 1 . The cost of repairs and the market value should refer to the same time period. Given that property values are usually the current ones, the cost of repairs is converted to present value prices. Also, the adopted prices should be adequately decreased relating to the actual maintenance conditions of the structure. As already mentioned, the cost of repairs has already been estimated for every affected property by inspectors during the field survey in order to calculate relief payments to flood victims. In the present analysis, this is converted in values of 2009 since the market values of affected buildings are estimated for that year.

The estimation of the market value of every property would have required extremely high effort in time and money to be implemented. In the present analysis, the methodology followed to quantify the asset values of the affected properties involved a classification of the structures per building use and type. The assumption of uniformity of the replacement values of floodaffected properties that belong to the same type holds true. The methodologies for the evaluation of property values and the classification of elements at risk are described in the following paragraph.

\subsubsection{Evaluation of Property Values and Classification of Elements at Risk}

In Greece, property evaluation is performed based on specific rules, set by the state and it is relied upon a standard procedure. The outcome of a property evaluation is known as the 'market value'. A large number of elements related to the building structure and the land site influence the market value of a property: structure size, quality of construction materials, structure age, land zone etc. However, parameters that depend on the offer-demand rules of real estate business are not considered in the estimation of a market value, given that these are dynamic and unpredictable factors that are irrelevant with actual direct flood damage. On the contrary, the value of the building itself and the value of the land site where the building is located, are both diminished in case of a natural disaster.

Market value estimation is based on standardized guide sheets, issued per building use by the Hellenic Ministry of Economics. Building use categories are the residential, commercial and warehouse use. Other parameters taken into account are: (a) structure related ones such as 
the number of storeys, size, age, construction material; and (b) land-area related ones such as the value of the land zone (in $€ / \mathrm{m}^{2}$ ) and the orientation of the façade of a building e.g., to a street, square, public space. Also, the existence of a central heating system and of an elevator (for buildings of more than two storeys) is considered in the calculation of the market value of a residence. Finally, other special conditions, such as the historical value of the building or whether the building has been damaged before (e.g., due to earthquakes, floods etc.) are taken into account for the estimation of the market value.

The above parameters indicated the differentiation of building types. Types of floodaffected buildings are categorized as: (a) one-storey that represents buildings that were flood damaged only at the ground floor of maximum area size equal to $75 \mathrm{~m}^{2}$; (b) one-storey with basement that represents buildings that accommodate a basement and were damaged both at the basement and ground floor of maximum total area size equal to $120 \mathrm{~m}^{2}$; and (c) basement that represents buildings that suffer damages only at the basement of maximum area size equal to $50 \mathrm{~m}^{2}$. Figure 1 depicts three land zones that are identified within the boundaries of the flood-affected area of Moschato municipality. Zone B stands for $1,100 € / \mathrm{m}^{2}$, Zone C stands for $1,300 € / \mathrm{m}^{2}$ and Zone D stands for $1,200 € / \mathrm{m}^{2}$ (in values of 2002). Also, two classes of age (one of 16-20 years and one of 21-25 years), are taken into account for the calculation of the market value of the building types. Finally, regarding the construction material, it is assumed that residential buildings are constructed using reinforced concrete or brick, whereas commercial stores and warehouses are made only of concrete. Every category of building use is assigned to one or more building types given that during the field survey the flood damage was recorded per building use. Table 1 shows the identified building types over the building uses.

\subsection{Statistical Characteristics of the Dataset}

Descriptive statistics (average value, standard deviation) of the damage dataset were calculated and their graphical representation (box plots, bar charts) were obtained using the statistical software package SPSS Release 8.0.

It is generally observed that the average value of damage percentage per building over the total dataset equals to only $12 \%$, which means that direct damage to buildings due to inundation is low with respect to the average market values of the affected properties. This is an expected result since it agrees with the field observation that the rehabilitation of all flood-affected buildings required only repair work. Tables 2 and 3 present the statistical characteristics of the damage dataset per building type and per building use, respectively.

It is observed from Tables 2 and 3 that standard deviations are high in the case of basements and warehouses. Figure 2 a shows that the highest values of damage percentage $(\approx 30 \%)$ are concentrated on basement warehouses. This observation is partly justified by the fact that the highest inundation depths are observed at basements (see also Fig. 2b) and partly by the fact that the costly 'special damage' was in most cases observed at the basement of buildings.

Combining the descriptive statistics with both observations on flood conditions and on site observations led to the general conclusion that the differences in spatial distribution of damage

Table 1 Identified building types per building use in the flood affected area of the Moschato municipality

\begin{tabular}{llll}
\hline & One-storey & One-storey with basement & Basement \\
\hline Residential use & $\sqrt{ }$ & $\sqrt{ }$ & $\sqrt{ }$ \\
Commercial use & $\sqrt{ }$ & $\sqrt{ }$ & $\sqrt{ }$ \\
Warehouse & $\sqrt{ }$ & $\sqrt{ }$ & \\
\hline
\end{tabular}


Table 2 Statistical characteristics of damage dataset per building type

\begin{tabular}{lrll}
\hline Building type & Number of buildings & $\begin{array}{l}\text { Average value of damage } \\
\text { percentage [\%] }\end{array}$ & $\begin{array}{l}\text { Standard deviation } \\
\text { of damage percentage [\%] }\end{array}$ \\
\hline One storey & 100 & 9.77 & 4.90 \\
One storey with basement & 8 & 6.95 & 1.23 \\
Basement & 21 & 25.39 & 9.45 \\
\hline
\end{tabular}

percentage follow the differences between the building types. Statistical analysis showed that damage percentage values are almost the same at low water depths for all available building types, whereas they differ gradually as water depth rises: given that the one-storey buildings with basement are usually elevated higher than the one-storey ones, the first ones had a smaller area inundated at a given water depth.

Finally, we observed that flood damage did not depend on the construction material since the majority of flood-affected building structures is constructed of concrete.

\section{Development of Local Relationships between Flood Depth and Damage Percentage}

The relationship between flood depth and damage percentage is statistically obtained. Related statistical analysis comprises parametric fitting of functions of various analytical forms, evaluation of the goodness of fit and determination of confidence and prediction bounds. Curve fitting is the process of constructing a mathematical function that best fits to a series of data points, possibly subject to constraints. A fitted function summarizes the relationship between flood depth (independent variable $x$ ) and damage percentage (dependent variable $y$ ). Statistical analyses on data per building use and per building type did not result in acceptable curve fitting due to the limited size of sub-samples. Therefore, the analysis is restricted to data per building use.

The Curve Fitting Toolbox software that operates in the MATLAB technical computing environment was used for data pre-processing, i.e., excluding outliers and smoothing, and curve fitting. The Least Squares Method was employed for the estimation of the parameters of the tested functions. Several function forms have been examined to provide a best fit function for original datasets, but, even for the best fitting functions (that is the power function), the determination coefficient $\left(R^{2}\right)$ remained far below the boundary value of 0.5 . Possible reasons for the weak correlation between variables $x$ (flood depth) and $y$ (damage percentage) are: (1) flood characteristics other than flood depth, e.g., flow velocity and flood duration, may contribute significantly to direct flood damage to buildings; (2) variations in building structure and material, and differences in ground-floor elevation cause a different degree of flood susceptibility for every building; (3) human error in recording and measuring direct flood

Table 3 Statistical characteristics of damage dataset per building use

\begin{tabular}{lllc}
\hline Building type & Number of buildings & $\begin{array}{l}\text { Average value of } \\
\text { damage percentage [\%] }\end{array}$ & $\begin{array}{l}\text { Standard deviation } \\
\text { of damage percentage [\%] }\end{array}$ \\
\hline Residential use & 87 & 9.58 & 2.93 \\
Commercial use & 17 & 6.13 & 2.54 \\
Warehouse & 25 & 25.09 & 17.31 \\
\hline
\end{tabular}



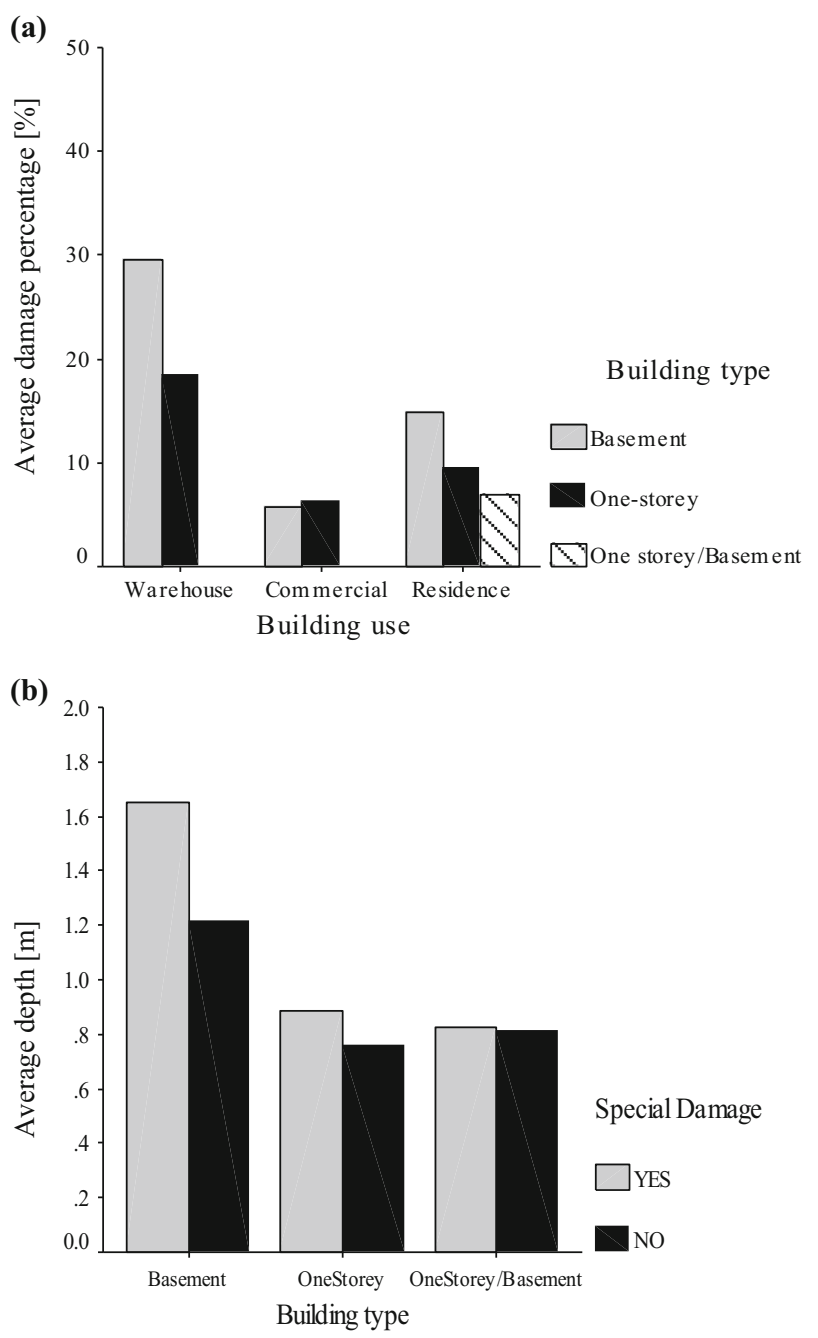

Fig. 2 a Average damage percentage vs building use per building type; $\mathbf{b}$ Average depth vs building type considering special damage

damage during site inspection cannot be considered negligible; (4) additional uncertainty is imported in the calculation of damage percentage due to the usage of average market value.

Curve fitting can involve the smoothing process, during which a "smooth" function is constructed that approximately fits the data. Smoothing of original damage datasets per building use produced new datasets of smoothed response values. The LOWESS (Locally Weighted Scatterplot Smoothing) method is used which involves linear least squares fitting of a first-degree polynomial with a span of $25 \%$ of the range of $y$ (damage percentage values). Also, the Robust LOWESS smoothing method is employed which is resistant to outliers. The power function resulted as the best fit function type to the new smoothed damage datasets per building use. The determination coefficient, $R^{2}$, is considered as the statistical measure of the goodness-of-fit to data by applying the test of null hypothesis (Stuart et al. 1999). The 
determination coefficient, $R^{2}$, of curve fitting to the smoothed dataset per building use, resulted equal to 0.78 for residential use, 0.68 for commercial use and 0.71 for warehouse use.

Regarding the flood-affected residences, for flood depth values between 0 and $1 \mathrm{~m}$, the best fit resulted in a descending power function (named as 'PF1') which is not acceptable as a relationship between flood depth and damage percentage. Hence, 'PF1' was replaced by a function whose values are constant for all depths between 0 and $1 \mathrm{~m}$. The constant function equals to the average value of smoothed damage percentage values that correspond to water depths between 0 and $1 \mathrm{~m}$. For values of flood depth between 1 and $2 \mathrm{~m}$, the curve-fitting to smoothed dataset resulted in an ascending power function (named as 'PF2') whose parameters $a$ and $b$ were calculated equal to 8.20 and 0.45 , respectively. The graphical extrapolation of function 'PF2' for flood depth values between 2 and $4 \mathrm{~m}$ with $95 \%$ confidence bounds and for residential use is presented in Fig. 3.

The developed power functions are the direct mathematical outcome of a statistical analysis. Given that $x$-values (flood depths) are usually recorded in the field or simulated in intervals (e.g., at $0.20 \mathrm{~m}$ ), it was decided that the developed power functions should be converted in step functions that are defined as finite combinations of constant functions for pre-selected intervals of $x$ values. Informally speaking, a step function is a piecewise constant function. The area of the definite integral of every derived step function approximately equals the area under the curve of every developed power function for the same set of values of the independent variable $x$ (flood depth). By implementing Simpson's rule, the power functions are converted to step functions.

To summarize the analysis results, the power function developed for flood-affected residences consists of three parts: (a) a constant function in the depth interval [0, 1); (b) a power function PF2 in the depth interval $[1,2)$; and (c) an extrapolated curve of power function PF2 in the depth interval $[2,6]$. The union of the above functions leads to a composite depthdamage step function for estimation of direct flood damage to residences located in Moschato area of Attica Prefecture.

Similarly, the development of depth-damage functions for both commercial and warehouse uses is based on statistically derived power-functions that are the best fits to smoothed damage

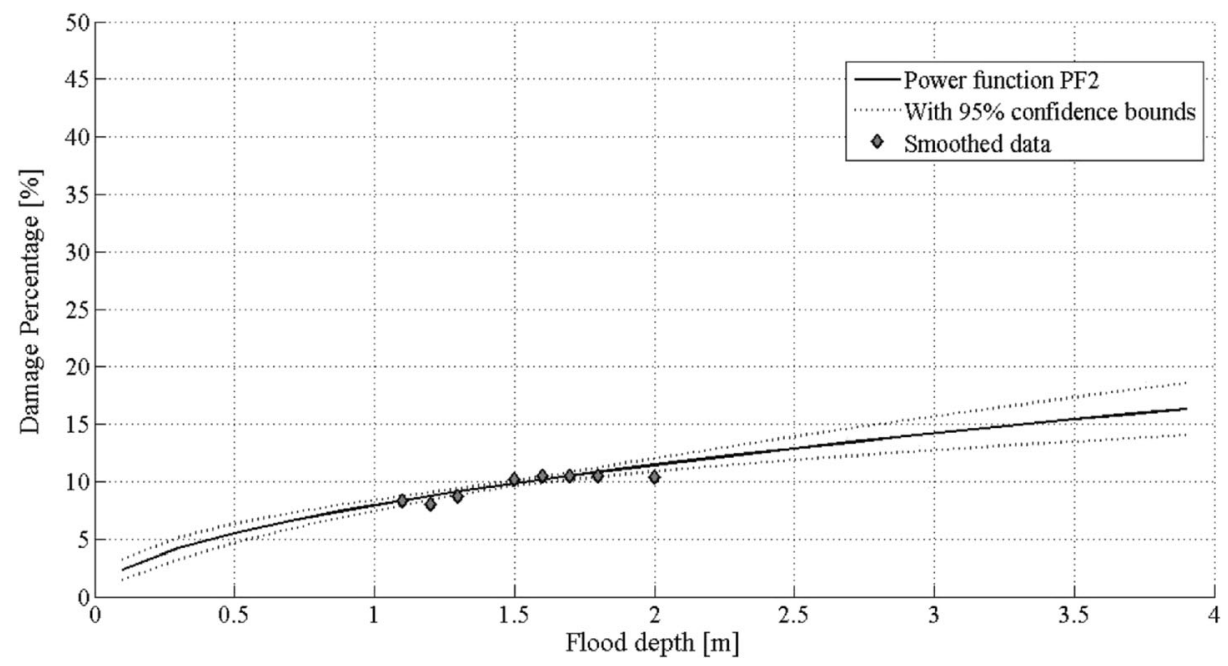

Fig. 3 Graphical representation of extrapolation of function PF2 for residential use with $95 \%$ confidence bounds 
dataset of the 2002 flood event. Figure 4 depicts the developed step functions for residential, commercial and warehouse uses, respectively.

It is noted that the depth-damage step functions for residences and commercial stores are of convex character which is the typical type of shape for a depth-damage curve. However, the step function for warehouse use has a concave form. The reasons for this are: (1) half of the warehouses were located at the ground floor and half of them at the basement; (2) the majority (more than $75 \%$ of the total number of affected warehouses) suffered from flood damage to the central heating system; (3) the replacement value of the 'special damage' was estimated in most cases equal to a quarter of the total replacement cost of a flood-affected warehouse. Hence, two factors were responsible for the high estimates of damage percentages for warehouse use and for the concave character of the respective step function: (a) the fact that 'special damage' occurred at least at $1.5 \mathrm{~m}$ flood depth indoors; and (b) the fact that the market value of a warehouse was evaluated very low.

\section{Comparison with Other Depth-damage Functions for Residential Use}

\section{1 'Moschato Step Function' Compared with Several Generalized Depth-damage Functions}

The depth-damage function of the case study was compared to depth-damage functions of the same building use that have been developed in the past using totally different spatial levels of damage analysis. Hence, the 'Moschato step function' for residential use is compared with a group of several generalized depth-damage functions, which are all developed for characteristic types of residences in different Districts of the USA by the US Army Corps of Engineers (USACE) during the 1970s and 1980s (USACE 2000; Appelbaum 1985; Debo 1982; FIA 1974). Those depth-damage functions not only are not site-specific, but also are generalized at

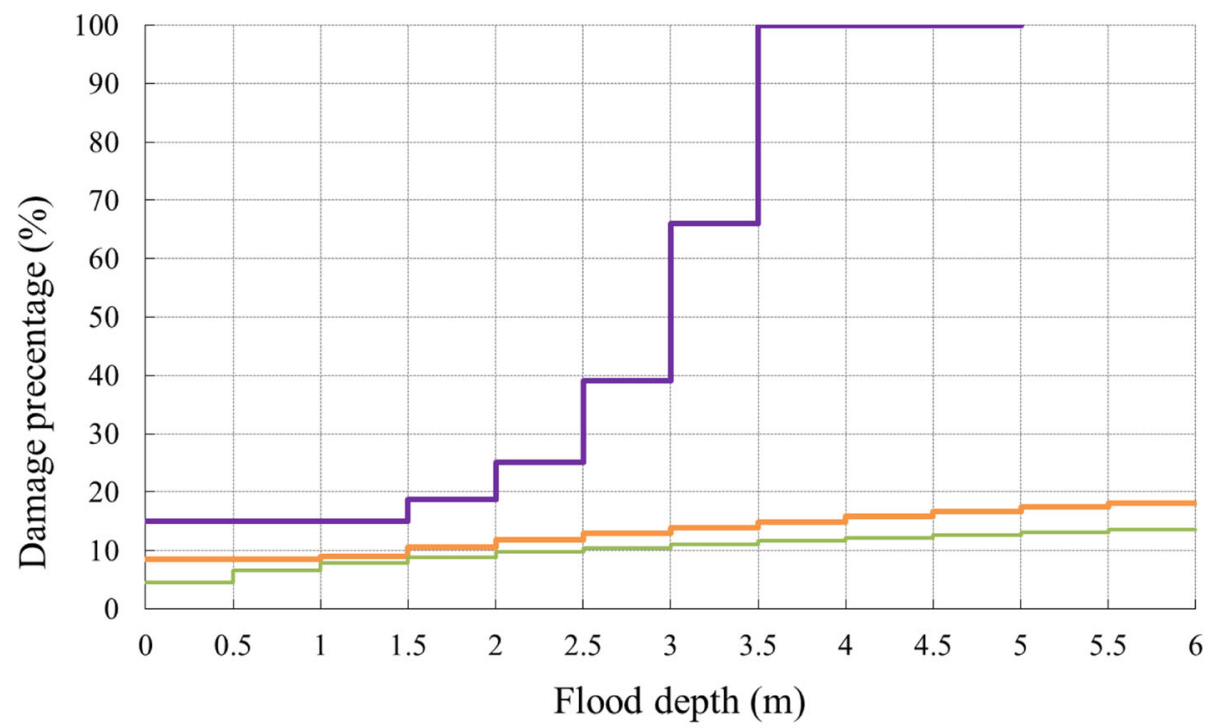

- Moschato step function for residence use - Moschato step function for commercial use

-Moschato step function for warehouse use

Fig. 4 Depth-damage step functions for residential, commercial and warehouse use 
a regional level so that they can be applied in all communities within the District jurisdiction, whereas the present analysis deals with very small urban watersheds.

Damage percentage estimation, however, for both the Appelbaum (1985) and Federal Insurance Administration (FIA) curves, has been based on actual, ex-post flood damages. Regarding Appelbaum's damage analysis, a relationship was derived between the replacement cost and the physical attributes of the structure obtained in the field (e.g., number of storeys, measured area of the house, and construction material). A similar methodology is followed in the present analysis for the derivation and evaluation of the characteristic building types of residence. Regarding the FIA relationship, the damage analysis was based on empirical flood claims data generated over several years.

Depth-damage functions should ideally be developed for the characteristic building types of each study area as it occurs in the present study. However, since developing site specific relationships is time consuming and expensive, the Appelbaum and FIA curves, presented in Fig. 5, are generalised depth-damage relationships for multi-storey, no basement type of residential building similar to the one used in the present study. Debo (1982) developed synthetic curves by using the results from an economic computer model and its application to generalized damage data in Georgia.

Regarding the USACE curves, presented in Fig. 5, these take into account data collected from major flood events that occurred in various parts of the United States in 1996, 1997 and 1998 (USACE 2000). Damage estimates are based on losses from flood victim records. The depth-damage percentage functions represent a substantive improvement over other generalized depth-damage functions, such as the Flood Insurance Administration (FIA) function.

Figure 5 visualizes the differences in the procedures followed to develop the depth-damage curves. It is noted that the generalized curves, i.e., the 'Appelbaum', 'Debo', 'FIA' and 'USACE' curves, result in significantly higher percent damage estimates than the sitespecific (i.e., the Moschato and the Palermo step functions). Besides the significant differences

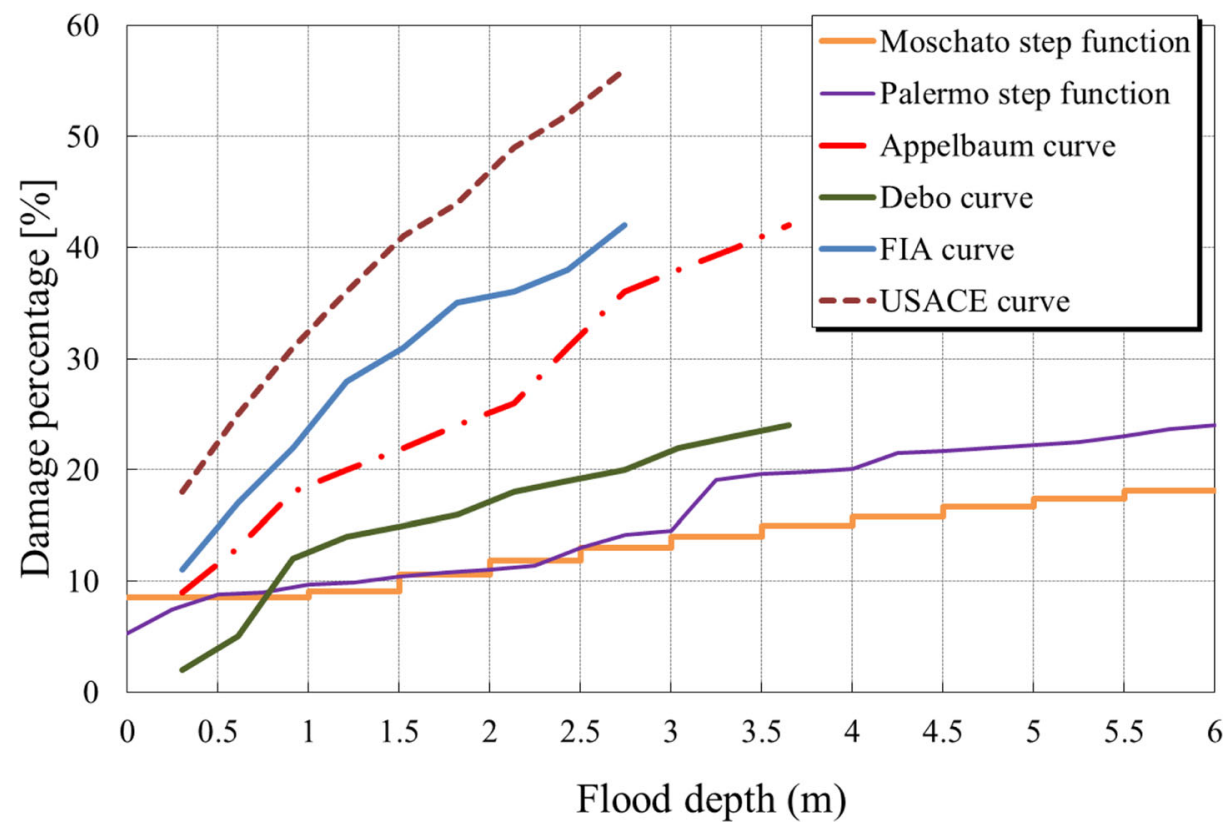

Fig. 5 Comparison of generalized depth-damage functions for residential use with Moschato step function 
between the generalized and the site-specific functions in regard to the source of damage data, the spatial level of damage analysis and the evaluation of the replacement costs, the type of construction material is a crucial factor that enhances differences in damage estimates since the most flood-affected residences in the United States is either made of bricks or wood, whereas in Europe these are made of concrete. Obviously, performing detailed local field work to identify characteristic building types makes a big difference in the estimation of the direct flood damage to residential structures.

In the following section, the Palermo step function is analyzed in comparison with the Moschato step function in order to find similarities and differences between the two sitespecific, detailed damage studies.

\subsection{Moschato Step Function vs. Palermo Step Function}

The extent to which the local conditions of a case study affect the result of direct damage estimation to residential buildings is further investigated by comparing the Moschato step function with a site-specific function developed by Oliveri and Santoro (2000) for the urban area of Palermo, Sicily, Italy. That depth-damage function has been developed by means of local detailed studies for the "Centro Storico" area, city of Palermo, specifically taking into account monuments and other estates of cultural or artistic significance. Damage was calculated as a percentage of damaged property value, whose calculation was based on the structural replacement cost. The determination of the depth-damage percentage relationship was carried out considering two 'prototype structures', with two and four storeys, respectively. The selected one for comparison is the one with four storeys, referenced as the 'Palermo step function' for the rest of the present analysis.

In the following section differences and similarities in damage datasets are examined and differences are explained by related causative factors, such as structural or architectural features of buildings.

\subsubsection{Similarities and Differences in Damage Datasets}

Strong similarities exist in damage datasets, the analysis methods followed and the case studies themselves. The main common features are: (1) Similar climatic, meteorological and discharge conditions since both study areas belong to the Mediterranean region; (2) small urban watersheds; (3) same type of flood: flooding occurs due to inadequate conveyance capacity of sections of the trained river that crosses each urban area under study; (4) both areas are built up areas of high density of multi-storey buildings, located in the centre; (5) the most common land use in both study areas is that of residential dwellings, but also different building types were identified; (6) basic construction material is either reinforced concrete or bricks; (7) detailed local field work offered the identification of different building types by investigating the external appearance of structures, the number of storeys and the presence of a basement; (8) the spatial distribution of building types surveyed in each study area is assumed to be the same in the whole area; (9) by grouping the identified building types, 'prototype structures' or characteristic building types are determined for the damage estimation process; (10) the same definition of damage percentage is employed in both study areas (percentage of property value, which is lost); (11) in both cases the damage estimate is the sum of the replacement costs of all flood-affected components of a 'prototype structure' by excluding building contents; (12) evaluation of the property values is performed per building type; and (13) the estimated property values are the recent ones, and are adequately decreased relating to the actual maintenance conditions of the structure. 
The main differences are summarized as follows: (1) In the Moschato case study, water depth observations were recorded at the interior of a building using as reference point the ground floor area, whereas, in the Palermo case, for almost all the analyzed structures, the height of pavement, which lies about $0.25 \mathrm{~m}$ above the road level, has been supposed to be the water depth at which damage begins; this difference has been taken into account in the comparison of the two depth-damage functions; (2) the source of flood hydraulic data is different: in the Moschato case, actual flood depth observations were used, whereas in the Palermo case the results of flood simulations were used; (3) the source of damage data is also different: in the Moschato case, damage estimation was based on relief payment data (see section 3.2) estimated after the flood event; however, the actual damage data, quantified in the field, was evaluated by using the overall replacement cost of the flood-affected components of every affected structure, whereas in the Palermo case, damage estimation is based on theoretical damage data; (4) the flood-affected property value estimation method is different: in the Moschato case, the market value is taken into account which considers both the replacement cost of the building structure and the value of the land zone that the property belongs to; in the Palermo case, the total cost for replacing the structure with another one, having the same size and use as the existing one, is considered; (5) regarding the property evaluation process, in the Palermo case the building content (furniture and appliances) is taken into account, with the assumption that the value of the contents is equal to $15 \%$ of the total value of the structure for all building types; in the Moschato case, only the damage to a specific component (i.e., the central heating system) that can be considered as building content is taken into account.

\subsubsection{Comparison of Depth-damage Functions}

It is noted that the prediction of damage percentage values based on the Moschato step function and the Palermo step function gives similar outcomes. The values are quite similar for low water depths, while they differ slightly when flood depth rises; for water depths less than $3 \mathrm{~m}$ which is approximately the distance between the ground floor and the ceiling of a building floor, the damage percentage values are similar whereas, for water depths higher than $3 \mathrm{~m}$, the difference of the two functions in terms of damage percentages is almost constant and equal to $5 \%$.

By applying the Palermo function to the flood depth observations of Moschato study area, the total damage amount is estimated almost $10 \%$ lower than the total actual damage amount. This result is expected since the majority of flood data concentrates on depths smaller than $3 \mathrm{~m}$. In this range of depth values, the Palermo function gives slightly smaller damage predictions than the Moschato function.

\subsubsection{Transposing the Moschato and Palermo Functions for Assessment of Damage-frequency Relationship}

This subsection investigates the impact of transposing the two site-specific depth-damage functions, the Moschato and Palermo functions, to a third site with the purpose of estimation of the average annual damage. The selected third site is located within Erasinos basin $\left(203 \mathrm{~km}^{2}\right)$ in Eastern Attica Prefecture, Greece, which is described as a flood-prone area due to the inadequate drainage network subject to with human interventions. It comprises two main tributaries, Ag. Georgios and Erasinos streams, and a buffer zone $1 \mathrm{~km}$ wide alongside the 


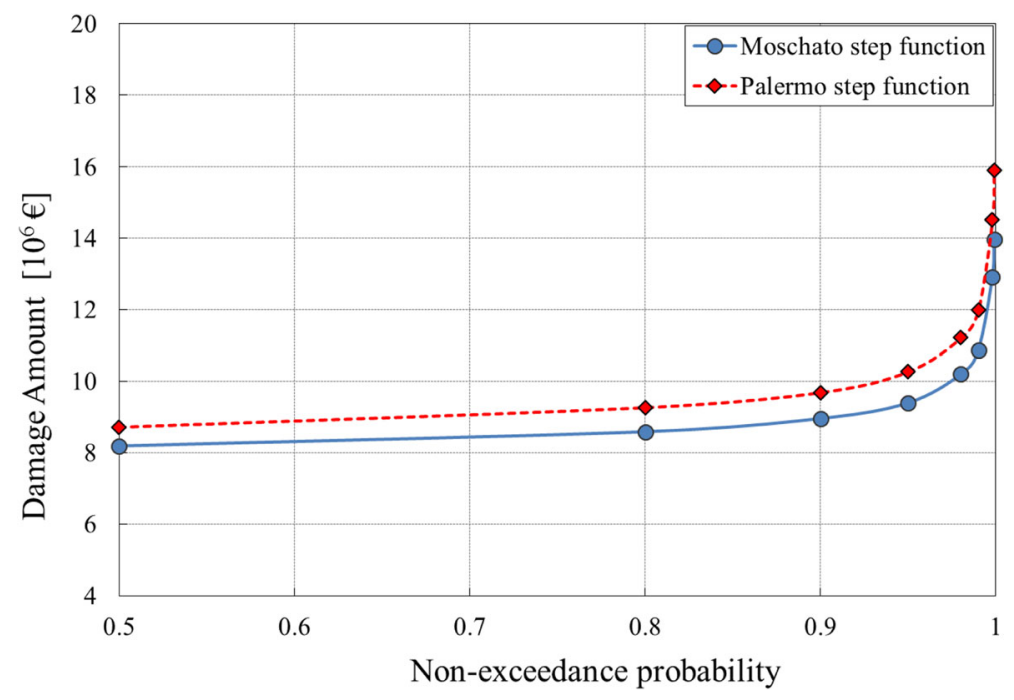

Fig. 6 Damage-frequency relationships by applying Moschato and Palermo step functions

streams. The simulation of the flood-prone area along the main tributaries under the specified flood scenarios was performed in HEC-RAS software v. 3.1.3.

A conventional approach for the estimation of the expected annual damage is based on the integration of a damage-frequency relationship over a definite interval of flood frequency values. The area under a damage-frequency relationship approximately equals the value of average annual damage.

The expected flood damages to residences under flood simulation runs are estimated by using: (a) the Moschato step function, and (b) the Palermo step function. The flood simulation runs were generated over a $25 \mathrm{~m} \times 25 \mathrm{~m}$ cell grid and the expected flood damage is estimated under eight (8) flood scenarios corresponding to flood return periods $T=2,5,10,20,50,100$, 500 , and 1,000 years.

Figure 6 depicts the two damage-frequency relationships derived by applying the two different depth-damage functions. It is noted that the application of the Palermo step function results in an average annual damage value equal to 5.6 million euros, higher than the one obtained (equal to 4.77 million euros) through the Moschato step function. This means that the majority of the flood simulation depths concentrates on depths higher than $3 \mathrm{~m}$ where the Palermo step function gives higher damage estimates than the ones resulting from the Moschato step function. The expected annual damages are found to differ by $9.2 \%$.

\section{Concluding Remarks}

The research study presented in this paper allowed us to share our experience with the hydrologic audience in regard to the development of flood depth-damage functions for the built environment. This is summarized in the following:

- Our search for flood damage data confirmed that these are really rare to a degree much higher than that of hydrometric data; moreover, in some cases existing data are unavailable to analysts due to restrictions for privacy. 
- Damage data collection campaigns are very often designed and executed by a public service office with the only purpose of determining the eligibility of flood victims for governmental housing assistance. Their adequacy for flood damage estimation is ignored, which often results in inadequate sample sizes or approximations that enhance data uncertainty.

- It is recommended to use flood damage data at the building level which will later allow their spatial aggregation to any spatial level, possibly requiring fusion with other datasets.

- The damage percentage per building is used in this study, which is the ratio of the cost of repairs to the market value of the building. This results in depth-damage percentage functions or, else, relative depth-damage functions, which are more robust than depthdamage functions with regard to shifts in time. Of course, robusness is achieved at the expense of simplicity of calculations since market values of buildings have to be calculated.

- Building categorization already employed in data collection campaigns are unlikely to be sufficient to allow the construction of depth-damage functions of acceptable accuracy when raw data are used. In our case, smoothing was necessary so as to obtain acceptable accuracy in the function sought per category of building use.

- Efforts of further categorization within general categories of building use requires careful examination of all elements at risk and is a promising route to obtain depth-damage functions of acceptable accuracy. This, however, requires a large dataset which is rarely available.

- The fact that, in our case, spatial compatibility of the data of damage and depth was high, allows us to conclude that in cases of lower data compatibility (e.g., when simulated depths are used) the difficulties in obtaining acceptable functions will be even greater.

- A coarse representation of the depth-damage relationship in the form of a step function is sufficient given the uncertainties involved in the development of such functions.

- Regarding the transferrability of depth-damage functions to sites other than those where these have been developed, it is preferable to use other site-specific functions as reference functions after careful examination of similarities and differences in their determining factors (i.e., construction material of buildings, characteristics of data and the elements at risk, methods for constructing functions, etc.). However, small but systematic differences between reference functions can result in differences in the expected average annual damage estimates which may not be negligible. In our case, in which very similar depth-damage functions were used, this difference was in the order of $10 \%$.

Acknowledgments The authors thank Dr. Elisa Oliveri, first author of the published research study titled as "Estimation of urban structural flood damages: the case study of Palermo" for providing valuable information for the development of the 'Palermo step function'. The authors wish also to thank the former Hellenic Ministry for the Environment, Physical Planning and Public Works for giving access to direct flood damage data derived from the 2002 inundation incidents within Attica Prefecture. Finally, the support of the State Scholarship Foundation of Greece to the first author of the paper, for carrying out this research, is also acknowledged.

\section{References}

Appelbaum SJ (1985) Determination of urban flood damage. J Water Resour Plan Manag 111(3):269-283

Batelis S-C, Nalbantis I (2014) Potential effects of forest fires on streamflow in the Enipeas river basin, Thessaly, Greece. Environ Process 1(1):73-85

Bellos V, Tsakiris G (2014) Comparing various methods of building representation for 2D flood modelling in built-up areas. Water Resour Manag. doi:10.1007/s11269-014-0702-3 
Büchele B, Kreibich H, Kron A, Thieken A, Ihringer J, Oberle P, Merz B, Nestmann F (2006) Flood-risk mapping: contributions towards an enhanced assessment of extreme events and associated risks. Nat Hazards Earth Syst Sci 6:485-503

Debo TN (1982) Urban flood damage estimation curves. J Hydraul Div 108:1059-1069

Diakakis M, Mavroulis S, Deligiannakis G (2012) Floods in Greece, a statistical and spatial approach. Nat Hazards 62:485-500

Earthquake Rehabilitation Center (2010) Disaster delimitations. Earthquake Rehabilitation Center (ERC), Ministry of Public Works, Available at: http://www.yas.gr

Egorova R, van Noortwijk JM, Holterman R (2008) Uncertainty in flood damage estimation. Int J River Basin Manag 6(2):1-10

European Council (2007) EU Directive of the European Parliament and of the European Council on the estimation and management of flood risks (2007/60/EU)

FIA (1974) Depth-percent damage curves. Federal Insurance Administration, US Department of Housing and Urban Development

Kelman I, Spencer R (2004) An overview of flood actions on buildings. Eng Geol 73:297-309

Krzysztofowicz R, Davis DR (1983) Category-unit loss functions for flood forecast-response system evaluation. Water Resour Res 19(6):1476-1480

Macheras Consulting Engineers S.A. (2002) Rainfall and flood data of the event on the 8th of July 2002. Report for Technical Consulting of the Olympic works 2004 for the Ministry of Public Works and Environment

Merz B, Kreibich H, Thieken A, Schmidtke R (2004) Estimation uncertainty of direct monetary flood damage to buildings. Nat Hazards Earth Syst Sci 4(1):153-163

Merz B, Kreibich H, Schwarze R, Thieken A (2010) Assessment of economic flood damage. Nat Hazards Earth Syst Sci 10:1697-1724

Messner F, Meyer V (2005) Flood damage, vulnerability and risk perception, challenges for flood damage research. UFZ Discussion Papers:13/2005

Messner F, Penning-Rowsell E, Green C, Meyer V, Tunstall S, van der Veen A (2007) Evaluating flood damages: guidance and recommendations on principles and methods. FLOODsite Project Deliverable D9.1, Contract No: GOCE-CT-2004-505420

Meyer V, Messner F (2005) National flood damage evaluation methods - a review of applied methods in England, the Netherlands, the Czech Republic and Germany. UFZ-Diskussionspapiere 21/2005.

Motayed AK, Krishnamurthy M (1979) Impact of hydrological uncertainties on flood insurance. J Hydraul Div, Proceedings of the ASCE, 105(HY11):1454-1455

Nalbantis I (1995) Use of multiple-time-step information in rainfall-runoff modelling. J Hydrol 165:135-159

Nalbantis I, Lymperopoulos S (2012) Assessment of flood frequency after forest fires in small ungauged basins based on uncertain measurements. Hydrol Sci J 57(1):52-72

Oliveri E, Santoro M (2000) Estimation of urban structural flood damages: the case study of Palermo. Urban Water 2:223-234

Penning-Rowsell EC, Fordham M (1994) Floods across Europe: flood hazard assessment, modelling and management. Middlesex University Press, London

Pistrika A (2010a) Flood damage estimations based on flood simulation scenarios and a GIS platform. Eur Water $30: 3-11$

Pistrika A (2010b) Direct flood damage estimation in built environment/ PhD dissertation, School of Rural and Surveying Engineering, National Technical University of Athens, March 2010

Pistrika A, Jonkman SN (2009) Damage to residential buildings due to flooding of New Orleans after hurricane Katrina. Nat Hazards 54(2):413-434

Reese S (2003) Die Vulnerabilität des schleswig-holsteinischen Küstenraumes durch Sturmfluten. Fallstudien von der Nord- und Ostseeküste, Berichte aus dem Forschungs- und Technologiezentrum Westküste der Universität Kiel, Bd. 30. Dissertation zur Erlangung des Doktorgrades der MathematischNaturwissenschaftlichen Fakultät der Christian-Albrechts-Universität zu Kiel

Smith DI (1994) Flood damage estimation - a review of urban stage-damage curves and loss functions. Water SA 20(3):231-238

Stuart A, Ord K, Arnold S (1999) Kendall's advanced theory of statistics. Vol. 2A: classical inference \& the linear model, 6th ed. Lavoisier Librairie

Thieken AH, Ackermann V, Elmer F, Kreibich H, Kuhlmann B, Kunert U, Maiwald H, Merz B, Müller M, Piroth K, Schwarz J, Schwarze R, Seifert I, Seifert J (2008) Methods for the evaluation of direct and indirect flood losses. Proceedings of the 4th International Symposium on Flood Defense 'Managing Flood Risk, Reliability and Vulnerability' (CD-ROM), Toronto, Canada, May 6-8, 2008

Tsakiris G (2014) Flood risk assessment: concepts, modelling, applications. Nat Hazards Earth Syst Sci 14:13611369 
Tsakiris G, Bellos V (2014) A numerical model for two-dimensional flood routing in complex terrains. Water Resour Manag 28:1277-1291

Tsakiris G, Nalbantis I, Pistrika A (2009) Critical technical issues on the EU flood directive. Eur Water 25(26): 39-51

USACE (1980) Hydrologic Engineering Center, interactive nonstructural analysis package, user's manual USACE (1982) Hydrologic Engineering Center, structure inventory for damage analysis, user's manual USACE (1996) Risk-based analysis for flood damage reduction studies. Engineering Manual, Technical Report EM 1110-2-1619. United States Army Corps of Engineers

USACE (2000) Generic depth-damage relationships. United States Army Corps of Engineers 